\title{
Role of the vacuum pressure and temperature in the shape of metal Zn nanoparticles
}

\author{
ROBERTO LÓPEZ ${ }^{1, *}$, ENRIQUE VIGUERAS-SANTIAGO ${ }^{1}$, PEDRO E ACUÑA-AVILA ${ }^{1,4}$, \\ SUSANA HERNÁNDEZ-LÓPEZ ${ }^{1}$, GUSTAVO LÓPEZ-TÉLLEZ ${ }^{2}$, \\ ERASTO ARMANDO ZARAGOZA-CONTRERAS ${ }^{3}$, \\ CLAUDIA ALEJANDRA HERNÁNDEZ-ESCOBAR ${ }^{3}$, WILBER ANTÚNEZ ${ }^{3}$ \\ and NAYELY TORRES-GÓMEZ ${ }^{1,4}$ \\ ${ }^{1}$ Laboratorio de Investigación y Desarrollo de Materiales Avanzados (LIDMA), Facultad de Química, Universidad \\ Autónoma del Estado de México, Paseo Colón esquina Paseo Tollocan, C.P. 50120, Toluca, Estado de México, Mexico \\ ${ }^{2}$ Centro Conjunto de Investigación en Química Sustentable UAEM-UNAM, Carretera Toluca-Atlacomulco, \\ km 14.5, Unidad El Rosedal, C.P. 50200 Toluca, Estado de México, Mexico \\ ${ }^{3}$ Centro de Investigación en Materiales Avanzados, S.C., Miguel de Cervantes No. 120, C.P. 31109 Chihuahua, \\ Chih., Mexico \\ ${ }^{4}$ Estudiante del programa de Doctorado en Ciencia de Materiales de la Universidad Autónoma del Estado de México, \\ Paseo Colón esquina Paseo Tollocan, C.P. 50200, Toluca, Mexico
}

MS received 14 May 2015; accepted 6 July 2015

\begin{abstract}
Zinc (Zn) nanoparticles were fabricated by the high-vacuum thermal evapouration technique. The vacuum pressure was modified from $10^{-6}$ to 15 Torr and the substrate temperature was increased from room temperature to $100^{\circ} \mathrm{C}$ in order to evaluate the changes in the morphological and structural characteristics of the $\mathrm{Zn}$ nanoparticles. Well-faceted hexagonal disk shaped nanoparticles were formed at a vacuum pressure of $10^{-6}$ Torr with the substrate kept at room temperature. Aggregation and surface irregularities at the edges of the hexagonal nanodisks were observed with further increases in the vacuum pressure. The nanoscale characteristics of the nanodisks were lost at a vacuum pressure of $10^{-6}$ Torr and heating the substrate at $100^{\circ} \mathrm{C}$. The nanodisks were transformed into $\mathrm{Zn}$ wires at a vacuum pressure of $15 \mathrm{Torr}$ with a substrate temperature of $100^{\circ} \mathrm{C}$. It is suggested that the initial stages of the growth of the $\mathrm{Zn}$ wires are governed by the agglomeration of the $\mathrm{Zn}$ nanodisks since the structure of the wires was observed to be composed by stacked nanodisks.
\end{abstract}

Keywords. Zn; nanodisk; nanowire; vacuum pressure; evapouration.

\section{Introduction}

Historically, zinc ( $\mathrm{Zn}$ ) has been successfully employed as building block for fabrication of batteries, ${ }^{1}$ anticorrosion coatings ${ }^{2}$ and structural alloys. ${ }^{3}$ Metallic $\mathrm{Zn}$ has a low melting point of $419^{\circ} \mathrm{C}$ and a hexagonal crystal structure with lattice constants of $a=0.2665$ and $c=0.4947 . .^{4}$ Most reports on electronic applications related to elemental $\mathrm{Zn}$ have been focused on the generation of semiconductor compounds such as $\mathrm{CdZnTe},{ }^{5} \mathrm{ZnSe},{ }^{6} \mathrm{TeZn}^{7}$ and $\mathrm{ZnO} .{ }^{8}$ In recent times, $\mathrm{Zn}$ nanowires have been fabricated with the aim that the one-dimensional effects should improve the superconducting coherence length of $\mathrm{Zn}$, which is almost an order larger than those of other metals. ${ }^{9}$

In addition to $\mathrm{Zn}$ nanowires, $\mathrm{Zn}$ nanoplates or nanosheets ${ }^{10,11}$ have also been prepared for fabrication of flat nanostructures, which are important for several technological

\footnotetext{
*Author for correspondence (lorr810813@gmail.com)
}

applications. ${ }^{12-15} \mathrm{Zn}$ nanostructures have been prepared by electrochemical methods, ${ }^{9}$ thermal reduction of $\mathrm{ZnO}^{16}$ and thermal evapouration. ${ }^{10}$ Among them, thermal evapouration is a simple method in which a material is heated to the point of evapouration and then is deposited on a substrate surface. In deposition by thermal evapouration, the substrate temperature and the vacuum pressure have proven to be the main experimental parameters in determining the shape of the deposited nanostructure. ${ }^{17}$ Although this technique has been successfully used in the preparation of $\mathrm{Zn}$ nanowires or nanodisks, the control over the morphology of the synthesized products remains as a challenge. For example, in vapourphase transport processes, it has been found that in similar growth conditions, $\mathrm{Zn}$ nanowires ${ }^{18}$ or $\mathrm{Zn}$ nanosheets ${ }^{19}$ have been collected on the inner walls of a quartz tube. In the present work, $\mathrm{Zn}$ nanodisks and wires were deposited by thermal evapouration using different vacuum pressures and temperatures. It was found that the substrate temperature favours the formation of curved $\mathrm{Zn}$ wires, which are composed by stacks of $\mathrm{Zn}$ nanodisks. 
Table 1. Experimental parameters used for deposition of $\mathrm{Zn}$ nanoparticles by thermal evapouration.

\begin{tabular}{lccclr}
\hline Sample & $\begin{array}{c}\text { Vacuum } \\
\text { pressure (Torr) }\end{array}$ & $\begin{array}{c}\text { Substrate temperature } \\
\left({ }^{\circ} \mathrm{C}\right)\end{array}$ & $\begin{array}{c}\text { Deposition } \\
\text { time }(\mathrm{h})\end{array}$ & $\begin{array}{c}\text { Morphology of the Zn } \\
\text { structures }\end{array}$ & $\begin{array}{c}\text { Mean size } \\
(\mathrm{nm})\end{array}$ \\
\hline 1 & $10^{-6}$ & Room temperature & 1 & Well-faceted hexagonal disk & 300 \\
2 & $10^{-6}$ & 100 & 1 & Well-faceted hexagonal disk & 1400 \\
3 & $10^{-4}$ & Room temperature & 1 & Irregular-faceted disk & 950 \\
4 & 15 & Room temperature & 1 & Aggregates of Zn disks & 600 \\
5 & 15 & 100 & 1 & Wires & 1000 \\
\hline
\end{tabular}

\section{Materials and methods}

$\mathrm{Zn}$ nanoparticles were prepared by the thermal evapouration technique in a high-vacuum resistive evapouration deposition system (Intercovamex TE12). Aluminium foils $(20 \times$ $20 \mathrm{~mm}$ ) were used as substrates and fixed on a substrate holder about $30 \mathrm{~cm}$ above a molybdenum boat filled with $50 \mathrm{mg}$ of pure $\mathrm{Zn}$ shavings (99.99\%). Once the vacuum pressure of the chamber was pumped to $2 \times 10^{-6}, 2 \times$ $10^{-4}$ or 15 Torr, the molybdenum boat was heated by raising the electrical current with a rate of $3.3 \mathrm{~A} \mathrm{~min}^{-1}$, reaching a current of $124 \mathrm{~A}$ and holding it there for $60 \mathrm{~min}$, with no carrier gas introduced. The substrate was kept at room temperature. Further experiments at $10^{-6}$ and 15 Torr, at $100^{\circ} \mathrm{C}$ were performed to evaluate the effect of heating the substrate on the morphology of the $\mathrm{Zn}$ nanodisks. Table 1 summarizes the experimental parameters used for deposition of $\mathrm{Zn}$ nanoparticles. After the synthesis of the $\mathrm{Zn}$ nanoparticles, the chamber was naturally cooled down to room temperature. The products were characterized by field-emission scanning electron microscope (FESEM, JEOL JSM-6510LV) with an acceleration voltage of $20 \mathrm{kV}$. The structural analysis was carried out using a high-resolution transmission electron microscope (HRTEM, JEM-2200FS) with an acceleration voltage of $200 \mathrm{kV}$, and an X-ray diffractometer (XRD, Bruker D8 Advances) with a radiation of $\mathrm{CuK} \alpha(1.541 \AA)$.

\section{Results and discussion}

Figure 1 shows the XRD patterns for the products deposited at vacuum pressures in the range of $10^{-6}-15$ Torr, in which the substrate was kept at room temperature. The peaks for all samples were indexed to the hexagonal close-packed $\mathrm{Zn}$ structure (space group P63/mmc; JCPDS no. 04-0831), without the presence of $\mathrm{ZnO}$ peaks, which suggest that the products were not oxidized during the synthesis, even for those deposited at 15 Torr. It is observed a strong (002) preferred orientation in the pattern of the sample deposited at $10^{-6}$ Torr, which has been associated to the high surface area of $\mathrm{Zn}$ nanoparticles. ${ }^{10}$ The use of vacuum pressures of $10^{-4}$ and 15 Torr leads to the gradual reduction in the intensity of the (002) peak, suggesting that the size of the nanoparticles increases simultaneously with the vacuum pressure.

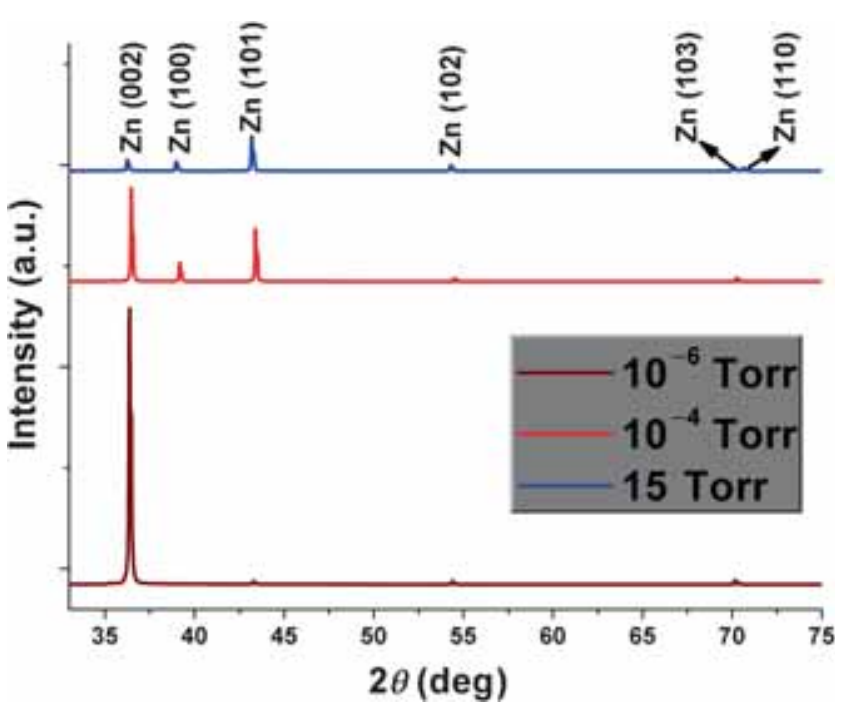

Figure 1. XRD pattern of the $\mathrm{Zn}$ nanodisks synthesized by the thermal evapouration technique in the vacuum pressure range of $10^{-6}-15$ Torr.
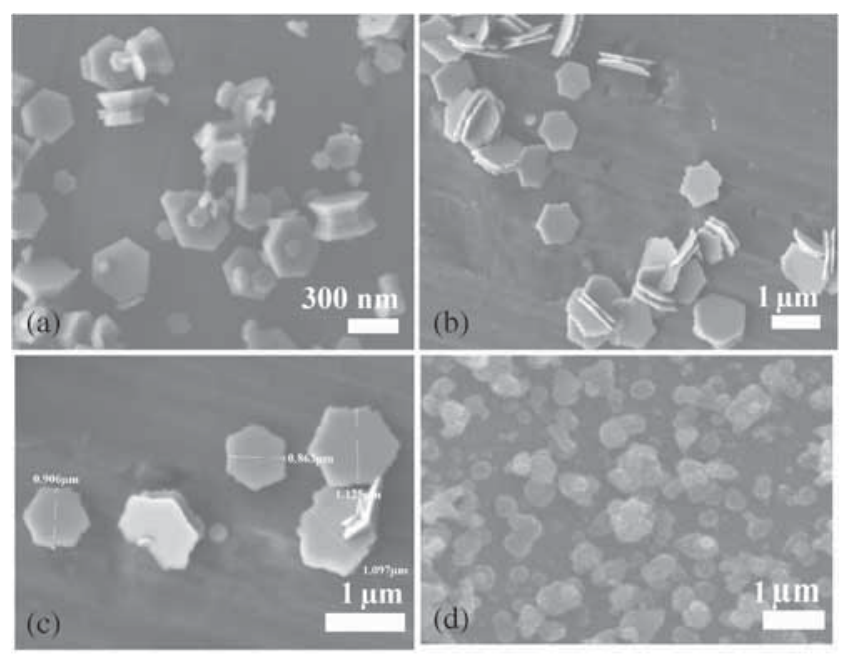

Figure 2. SEM images of the $\mathrm{Zn}$ nanodisks deposited by thermal evapouration at different vacuum pressures with the substrate kept at room temperature: (a) $10^{-6}$, (b) and (c) $10^{-4}$ and (d) 15 Torr.

The morphology of the products deposited at vacuum pressures in the range of $10^{-6}-15$ Torr with the substrate kept at room temperature is shown in figure 2. Figure 2a shows the 
SEM image of the $\mathrm{Zn}$ products synthesized at a pressure of $10^{-6}$ Torr. Well-faceted hexagonal $\mathrm{Zn}$ nanodisks with sizes in the range of 100-500 $\mathrm{nm}$ and thicknesses between 100 and $200 \mathrm{~nm}$ can be observed. No other morphologies were found, which suggest that only one growth mechanism was involved in the formation of the $\mathrm{Zn}$ nanodisks. Aggregates of $\mathrm{Zn}$ nanodisks with different sizes were also found, which could be evidence of vapour phase reactions. ${ }^{20}$ The pressure into the chamber was increased in order to evaluate the effect of the vacuum level in the morphological characteristics of the $\mathrm{Zn}$ nanodisks. In figure $2 \mathrm{~b}$, it is observed that $\mathrm{Zn}$ particles with sizes larger than those deposited at $10^{-6}$ Torr, were formed at a vacuum pressure of $10^{-4}$ Torr. This image also shows that the smooth shape was lost and surface irregularities at the edges of the $\mathrm{Zn}$ nanodisks were formed. The mean size of the $\mathrm{Zn}$ nanodisks is found above $800 \mathrm{~nm}$ (figure 2c). No significant changes are observed with further increase in the pressure to 15 Torr. The morphology is composed by agglomerates of $\mathrm{Zn}$ nanodisks with sizes under $1 \mu \mathrm{m}$ (figure $2 \mathrm{~d})$. Although the smooth surface of the hexagonal nanodisks deposited at $10^{-6}$ Torr is destroyed with increases in the vacuum pressure, it seems that not exceed $1 \mu \mathrm{m}$ in particle size even for the sample deposited at 15 Torr.

Unlike other nanostructured materials, metal Zn develops into two main morphologies: $\mathrm{Zn}$ nanodisks or nanowires. With the aim to determine the experimental conditions that benefits the growth of $\mathrm{Zn}$ nanowires, the substrate was heated at $100^{\circ} \mathrm{C}$ with two different vacuum pressures: $10^{-6}$ and 15 Torr (figure 3). In figure 3a, it is observed the SEM image of the sample deposited at $10^{-6}$ Torr with the substrate temperature kept at $100^{\circ} \mathrm{C}$. The morphology is composed by well-faceted hexagonal $\mathrm{Zn}$ disks. However, the mean size of the disks is found above $1 \mu \mathrm{m}$ and their thicknesses above $500 \mathrm{~nm}$, which in contrast with the nanodisks deposited at room temperature shows evidence that the nanoscale characteristics of the $\mathrm{Zn}$ nanodisks were lost by heating the

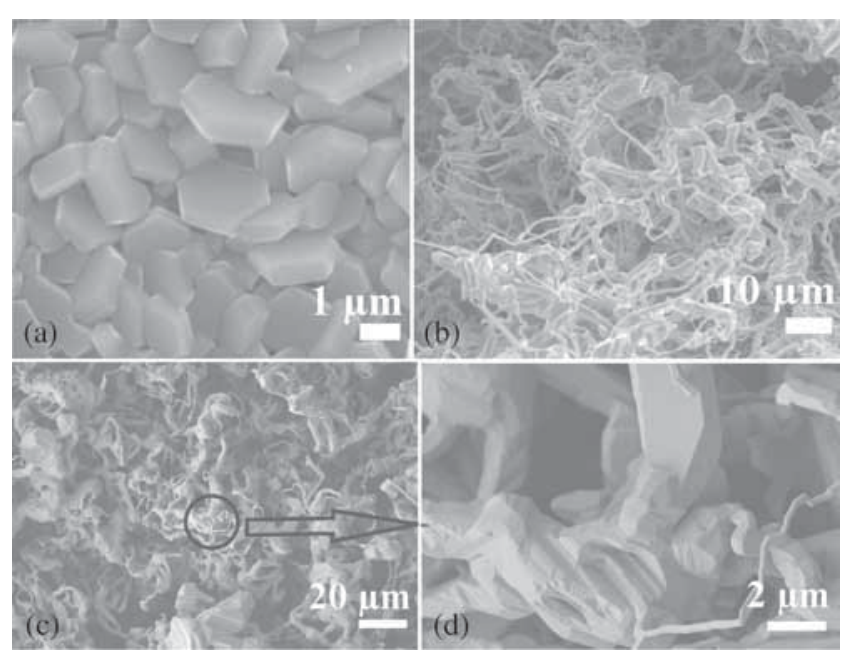

Figure 3. SEM images of the $\mathrm{Zn}$ nanodisks deposited by thermal evapouration at (a) $10^{-6}$ and (b-d) 15 Torr. The substrate was heated at $100^{\circ} \mathrm{C}$. substrate. The $\mathrm{Zn}$ nanodisks were transformed into $\mathrm{Zn}$ wires with serpentine geometries and irregular surfaces by using a vacuum pressure of 15 Torr and a substrate temperature of $100^{\circ} \mathrm{C}$ (figure $3 \mathrm{~b}$ ). The morphology observed in figure $3 \mathrm{~b}$ has been previously reported by other workers. ${ }^{18,21,22}$ The FESEM image of figure $3 \mathrm{~b}$ shown in figure $3 \mathrm{c}$, shows that the structure of the $\mathrm{Zn}$ wires is formed by $\mathrm{Zn}$ nanoparticles. High-magnification FESEM image in figure $3 \mathrm{~d}$ exhibits that the $\mathrm{Zn}$ nanodisks merged with each other to develop into $\mathrm{Zn}$ wires.

Since the best definition in the morphological characteristics for the $\mathrm{Zn}$ particles was observed at the higher vacuum level with a pressure of $10^{-6}$ Torr, and by considering that disk-shaped particles were found in all samples, the structure of the $\mathrm{Zn}$ nanodisks deposited at a pressure of $10^{-6}$ Torr was also characterized by HRTEM (figure 4). The dark-field image (figure $4 \mathrm{a}$ ) confirms that the nanodisks have a hexagonal shape with a $120^{\circ}$ angle between each pair of adjacent edges. The different contrast observed along the side facets of the particle suggests that hexagonal nanodisks with low thickness attach over each other during the growth process. This oriented attachment is energetically favoured because bonding between nanodisks reduces the overall energy by removing the surface energy associated with dangling bonds. ${ }^{23}$

The HRTEM image shows one corner of a single nanodisk (figure $4 \mathrm{~b}$ ). The lattice fringes in some zones are not perfectly aligned, suggesting that the stacked $\mathrm{Zn}$ nanodisks are slightly rotated. Analysis of the selected area diffraction (SAED) pattern (inset of figure $4 \mathrm{~b}$ ) confirms that the $\mathrm{Zn}$ nanodisk exhibits a single crystalline nature. The SAED pattern is composed of two sets of spots, the outer one (marked by the red arrow) corresponds to a lattice space of $0.24 \mathrm{~nm}$, matching well with the (002) planes of $\mathrm{Zn}$. The inner spots (marked by the white arrow) correspond to a measured lattice space of $0.28 \mathrm{~nm}$ consistent with the distance of (100) planes of $\mathrm{ZnO}$. The alignment of both set of spots suggests an epitaxial relationship between the two lattice systems. As metallic $\mathrm{Zn}$ is reactive, a thin $\mathrm{ZnO}$ layer could be formed on the surface of some $\mathrm{Zn}$ nanodisks upon exposure to the

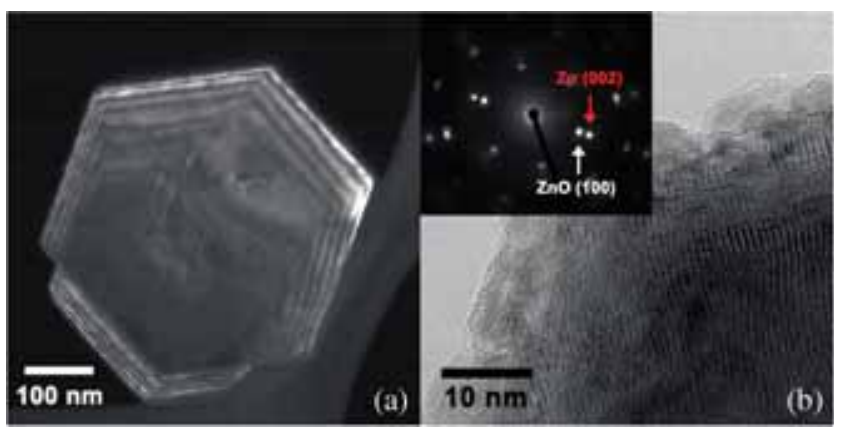

Figure 4. TEM images of a single hexagonal $\mathrm{Zn}$ nanodisk deposited at a vacuum pressure of $10^{-6}$ Torr: (a) dark-field image, (b) high-resolution TEM image from one vertice of the hexagonal structure. The inset shows the corresponding SAED pattern. 
atmosphere, although deeper atomic layers are still in the elemental form.

It is known that in vapour synthesis, the competition of the capture of impinged molecules by different surface planes under certain supersaturation conditions determines the final morphology of the nanostructure. The degree of supersaturation of a solute $\mathrm{A}$ in air at a temperature $T$ can be calculated by the saturation ratio $(S)$, described by the following equation:

$$
S=\frac{P_{\mathrm{A}}}{P_{\mathrm{A}}^{\mathrm{s}}(T)}
$$

where $P_{\mathrm{A}}$ is the partial pressure of $\mathrm{A}$ and $P_{\mathrm{A}}^{\mathrm{s}}$ the saturation vapour pressure of $\mathrm{A}$ in equilibrium with its liquid phase at the temperature of the substrate $T$. A low degree of supersaturation $(S>1)$, may benefits the growth of 1D nanostructures such as nanowires, nanotubes, nanobelts, among others. A high degree of supersaturation $(S \gg 1)$, favours spontaneous nucleation in the gas phase and nanostructures macroscopically seen as powders could be formed. ${ }^{24}$ As can be seen in equation (1), both pressure and temperature can be controlled to determine the degree of saturation. From the triple phase equilibrium diagram of $\mathrm{Zn}$, solid $\mathrm{Zn}$ begins to evapourate at temperatures at of $343^{\circ} \mathrm{C}$ and pressures below $10^{-2}$ Torr. $^{25}$ In similar experimental conditions where a low degree of supersaturation can be assumed, some workers have synthesized pure $\mathrm{Zn}$ nanowires. ${ }^{26,27}$ In thermal evapouration processes where the source of evapouration is placed away from the substrate, supersaturation conditions are usually controlled by the temperature gradient in the reaction furnace. ${ }^{28}$ The difference of temperatures between the evapouration zone and the substrate creates two saturation zones: one is a isothermal zone in the vicinity of the metal evapouration region, and the other one is a supersaturated vapour zone in which the temperature decreases along the distance from the evapouration zone. ${ }^{29}$ In our experiments, a high degree of supersaturation could be produced near the substrate since vapour pressure of $\mathrm{Zn}$ was higher than the partial pressure of $\mathrm{Zn}$, even in the experiment performed at 15 Torr. Although the growth mechanism for disk- and wire-like $\mathrm{Zn}$ nanostructures has been independently studied, the presence of $\mathrm{Zn}$ nanodisks in the structure of the $\mathrm{Zn}$ wires suggest that initial stages of the wire growth includes the $\mathrm{Zn}$ nanodisk formation and that the wire growth could be favoured by the substrate temperature. Since the substrate temperature was kept below the melting point of $\mathrm{Zn}$ in all experiments and that the process can be considered to be catyalyst-free, the growth of wire- and disk-like $\mathrm{Zn}$ nanostructures should follows a vapour-solid mechanism. Thus, the growth mechanism for the $\mathrm{Zn}$ nanodisks is proposed as follows:

The evapourated $\mathrm{Zn}$ atoms reach supersaturation in the gas phase near the substrate. These atoms condense to form $\mathrm{Zn}$ nuclei (also called seeds), and then grown into stable nuclei with further addition of $\mathrm{Zn}$ atoms. The hexagonal shape developed by the nanodisks can be explained on the basis of the anisotropic growth of the $\mathrm{Zn}$ crystal.
The total surface energy during nanocrystals growth is reduced by exposing surface planes that have low surface free energy, which for $\mathrm{Zn}$ is the $\{0001\}$ facet. The planes with higher surface energy grow faster than other planes to minimize the surface energy.

Thus, it is expected that the side facets of $\mathrm{Zn}$ are most favoured to the minimization of the total surface energy and hexagonal disks with a narrow distribution of thickness (100-150 nm) were formed.

The SEM image in figure $2 \mathrm{a}$ showed that the aggregation of the $\mathrm{Zn}$ nanodisks occurred mainly between tiny and big nanoparticles. However, in the TEM image (figure 4a), all stacked $\mathrm{Zn}$ nanodisks were observed to have comparable sizes. This difference could be explained by considering that in some cases the small $\mathrm{Zn}$ nuclei coalesce into bigger ones via oriented attachment, ${ }^{30}$ which is seen in the final morphology as assembly of $\mathrm{Zn}$ nanodisks with identical sizes. Moreover, it has been suggested that the formation of $\mathrm{Zn}$ nanodisks is related to surface processes, which includes formation of liquid droplets of $\mathrm{Zn}$ in substrate temperatures about the melting point of $\mathrm{Zn}\left(419^{\circ} \mathrm{C}\right) .{ }^{10}$ However, temperatures around $100^{\circ} \mathrm{C}$ and above could promote the aggregation of the $\mathrm{Zn}$ nanodisks and subsequently cause coalescence and growth of longitudinal arrays of stacked $\mathrm{Zn}$ nanodisks, which can be seen as curved nanowires.

\section{Conclusions}

The effect of the vacuum pressure and temperature on the morphological characteristics of $\mathrm{Zn}$ nanoparticles was studied. It was found that the size and morphology of the $\mathrm{Zn}$ nanoparticles can be controlled by varying experimental parameters such as vacuum pressure and temperature. Zn nanodisks with well-defined geometry can be formed by using a vacuum pressure of $10^{-6}$ Torr with the substrate kept at room temperature. The increase in pressure and temperature lead to the formation of micrometre $\mathrm{Zn}$ nanodisks or their transformation into wire-like-shaped structures.

\section{Acknowledgements}

This work was supported by CONACYT and PRODEPMéxico, proyecto de red 2014-2015. We wish to thank Laboratorio Nacional de Nanotecnología (CIMAV-Chihuahua) and C.E. Ornelas-Gutierrez for the support during this research.

\section{References}

1. Winter M and Brodd R 2004 Chem. Rev. 1044245

2. Weng D, Jokiel P, Uebleis A and Boehni H 1997 Surf. Coat. Technol. 88147

3. Murphy S and Savaskan T 1984 Wear 98151

4. Parish R 1977 The metallic elements (New York: Longman Inc.) 
5. Gan B, Wei T, Gao W, Zeng H and Hu Y 2014 Nucl. Instrum. Methods A 764193

6. Morkoc H, Strite S, Bao G, Lin M, Sverdlov B and Burns M 1994 J. Appl. Phys. 761363

7. Tablero C 2006 Sol. Energy Mater. Sol. Cells 90588

8. Rusu G, Rusu M and Apetroaei N 2007 Thin Solid Films 515 8699

9. Wang G, Tiang M, Kumar N and Mallouk T 2005 Nano Lett. 5 1247

10. Devan R, Lin J, Huang Y, Yang C, Wu S, Li Y and Ma Y 2011 Nanoscale 34339

11. Zhu Y and Bando Y 2003 Chem. Phys. Lett. 372640

12. Zhou M, Lou X and Xie Y 2013 Nano Today 8598

13. Sun $\mathrm{Z}$ and Chang H 2014 ACS Nano 84133

14. Pan $\mathrm{Y}$, Yin $\mathrm{X}$, Kwok $\mathrm{K}$ and Yang $\mathrm{H}$ Nano Lett. doi: 10.1021/nl502969g

15. Kwon O, Kim T, Lee J, Park S, Kang M, Lee J, Jang J and Yoon H 2013 Small 9248

16. Gao P, Lao C, Ding Y and Wang Z 2006 Adv. Func. Mater. 1653

17. Wu C, Wuu D, Lin P, Chen T and Horng R 2009 Nanoscale Res. Lett. 4377
18. Kar S, Ghoshal T and Chaudhuri S 2006 Chem. Phys. Lett. 419 174

19. Zhu Y and Bando Y 2003 Chem. Phys. Lett. 372640

20. Ohring M 1992 The materials science of thin films (San Diego, CA: Academic Press)

21. Kong X, Ding Y and Wang Z 2004 J. Phys. Chem. B 108 570

22. Liu J, Zhang Z, Su X and Zhao Y 2005 J. Phys. D: Appl. Phys. 381068

23. Penn R L and Banfield J F 1998 Science 281969

24. Xia Y, Yang P, Sun Y, Wu Y, Mayers B, Gates B, Yin Y, Kim $\mathrm{F}$ and Yan H 2003 Adv. Mater. 15353

25. Zhan L, Qiu Z and Xu Z 2009 Sep. Purif. Technol. 68397

26. Wang Q, Chen G and Zhou N 2009 Nanotechnology 20085602

27. Liu J, Zhang Z, Su X and Zhao Y 2005 J. Phys. D: Appl. Phys. 381068

28. Mohanty P, Kang T, Kim B and Park J 2006 J. Phys. Chem. B 110791

29. Onischuk A, Purtov P, Baklanov A, Karesev V and Vosel S 2006 J. Chem. Phys. 124014506

30. Huang F, Zhang H Z and Banfield J F 2003 J. Phys. Chem. B 10710470 